Alvarado-Reyes, N.G., Alvarado-Reyes, J.J. y Alfonso-Bernal, N.E. (2019). La Virgen del Rosario de Chiquinquirá. Un referente simbólico patrimonial en la consolidación del Estado nación en Colombia. Revista de Antropología y Sociología: VIRAJES, 21(2), 59-79. DOI: 10.17151/rasv.2019.21.2.4

\title{
La Virgen del Rosario de Chiquinquirá. Un referente simbólico patrimonial en la consolidación del Estado nación en Colombia
}

\author{
NIDIAN GIOVANNA ALVARADO-REYES* \\ JHON JAIRO ALVARADO-REYES** \\ NOHORA ELISABETH ALFONSO-BERNAL ${ }^{* * *}$
}

Recibido: 17 de febrero de 2019

Aprobado: 29 de abril de 2019

Artículo de reflexión

\begin{abstract}
* Administradora Turística y Hotelera, Magister en Patrimonio Cultural, Grupo de investigación para la Animación Cultural MUISUATA, Universidad Pedagógica y Tecnológica de Colombia-UPTC, Tunja, Boyacá, Colombia. Correo electrónico: nidian.alvarado@uptc.edu.co. (1) ORCID: 0000-0003-1065-1141 Google Scholar

** Abogado, estudiante de especialización en Derecho Constitucional, estudiante de Administración pública de la Escuela Superior de Administración Pública ESAP Grupo de investigación Primo Levi en Justicia Social, Universidad Pedagógica y Tecnológica de Colombia-UPTC, Tunja, Boyacá, Colombia. Correo electrónico: jhon.alvarado01@uptc.edu.co. (1) ORCID: 0000-0003-1216-091X. Google Scholar *** Doctora en Educación, Directora del Grupo de Investigación para la Animación Cultural MUISUATA, Profesora de tiempo completo de la Universidad Pedagógica y Tecnológica de Colombia-UPTC, Tunja, Boyacá, Colombia. Correo electrónico: nohora.alfonso@uptc.edu.co. (1) ORCID: 0000-0002-7831-7433. Google Scholar
\end{abstract}




\title{
Resumen
}

Este artículo analiza la patrimonialización de la Virgen del Rosario de Chiquinquirá en la formación del Estado nación en Colombia, para comprender cómo la activación de los referentes simbólicos de una cultura se ve mediada por la consecución de intereses políticos. Para su elaboración se realizó un análisis bibliográfico, así como una revisión de fuentes primarias y secundarias y de registros de trabajo de campo. Los resultados sostienen, a partir del hecho histórico de la Coronación de la Virgen del Rosario de Chiquinquirá, la necesidad que tienen los estados o los gobiernos, con sus políticas nacionales, de crear, inventar, seleccionar y en últimas activar referentes simbólicos de una cultura para imponer una versión de identidad nacional. Se concluye que la selección y activación de referentes simbólicos patrimoniales se convierten en un instrumento que legitima el comportamiento del Estado y justifica las acciones de puesta en valor de ahí en adelante.

Palabras clave: patrimonio cultural, identidad, Estado nación, culto religioso, Virgen del Rosario de Chiquinquirá.

\section{"Virgin of the Rosary of Chiquinquirá". A symbolic patrimonial reference in the consolidation of the Nation State in Colombia}

\begin{abstract}
This article analyzes the patrimonialization of the Virgin of the Rosary of Chiquinquirá in the formation of the Nation State in Colombia, to understand how the activation of the symbolic referents in the culture of a community is mediated by the attainment of political interests. For its elaboration, a bibliographic analysis was carried out, as well as a review of primary and secondary sources and records of field work. The results support, from the historical fact of the coronation of the Virgin of the Rosary of Chiquinquirá, the need that states or governments have, with their national policies, to create, invent, select and, ultimately, activate symbolic referents of a culture to impose a version of national identity. It is concluded that the selection and activation of patrimonial symbolic referents become an instrument that legitimizes the behavior of the State and justifies the actions of value from then on.
\end{abstract}

Key words: cultural heritage, identity, State Nation, religious cult, Virgin of the Rosary of Chiquinquirá. 


\section{Introducción}

— ste artículo es una reflexión derivada de la investigación titulada: Valoraciones y tensiones en el patrimonio religioso: fiesta de la Coronación de la Virgen del Rosario de Chiquinquirá (Colombia), proyecto cofinanciado por Colciencias y la Gobernación de Boyacá, convocatoria 733 de2015, a través de la Dirección de Investigación y Extensión de la Universidad Pedagógica y Tecnológica de Colombia. Esta reflexión toma como referente a la Virgen del Rosario de Chiquinquirá, símbolo religioso desde la Colonia, y describe su proceso de patrimonialización por medio de su activación en los primeros años del siglo $\mathrm{XX}$, cuando es coronada como patrona y reina de Colombia.

Este ejercicio académico resulta decisivo a la hora de pensar, desde una perspectiva de análisis, la manera en cómo la selección y la activación de referentes simbólicos, por ejemplo, los religiosos, en distintas épocas instrumentalizan intereses políticos.

En líneas generales en el apartado uno de este artículo, se recogen construcciones teóricas sobre cómo y cuándo comienza a definirse el patrimonio cultural desde un contexto específico. En este surgen discusiones, ámbitos y marcos legales que amparan la idea de que el proceso de patrimonialización de referentes simbólicos está dado desde estrategias de selección y activación no inocentes $y$, pocas veces, consensuadas.

A partir de la revisión de fuentes, el segundo apartado constituye el reconocimiento de elementos que validan la construcción histórica de la Virgen del Rosario de Chiquinquirá como un referente simbólico patrimonial. De igual forma, estos elementos dan validez a la materialidad de la creencia, el relato oficializado de la renovación y la producción identitaria local de Chiquinquirá, como un espacio desde la dimensión religiosa.

Como colofón y tercera parte de este artículo, mediante argumentos, se describen los valores patrimoniales surgidos alrededor del culto popular a la Virgen del Rosario de Chiquinquirá. Este, como referente simbólico en la configuración del Estado nación colombiano. De esta manera, se señala la necesidad que tenían las elites conservadoras de la época, de instrumentalizar unos intereses políticos con la Coronación de la Virgen. 


\section{Construcción del patrimonio cultural como elemento vinculante en el surgimiento del Estado nación}

El ser humano, sus acciones, formas y estilos de vida son construcciones sociales, ligadas a una noción de ser y pertenecer desde lo colectivo, donde las prácticas culturales y la producción simbólica y material resultantes, le permiten atribuir significados y valores que representan su identidad. Por tal razón, es necesario dar a conocer el contexto temporal y la manera en que comienza a vincularse la idea de patrimonio cultural con las relaciones establecidas entre el ser humano y los elementos que ha seleccionado como referentes simbólicos de su identidad. De la misma manera, es importante indicar cómo dichos referentes son usados por las clases hegemónicas y los poderes políticos para imponer versiones de identidad y, por lo tanto, instrumentalizar unos intereses. Así, el propósito de este apartado es vincular el referente simbólico patrimonial de la Virgen del Rosario de Chiquinquirá con la categoría de patrimonio cultural en un contexto específico del surgimiento del Estado nación.

\section{El patrimonio cultural: definición casi necesaria}

Es un consenso generalizado entre diversos autores (Arrieta, 2010; Prats, 1997; Llull- Peñalba, 2005), que el emergente concepto de patrimonio cultural surge con el movimiento de la Ilustración, hacia la segunda mitad del siglo XVIIl. Lo anterior, con base en que la cultura y las vivencias de "cada pueblo es visto por ilustrados y románticos como un elemento que sirve para identificarlo y sus testimonios materiales serían el testimonio de ese pasado (el de cada pueblo)" (Cuetos, 2011, p. 21). Sin embargo, las primeras concepciones de patrimonio cultural estuvieron estrictamente ligadas a los referentes simbólicos de carácter material, como monumentos o pinturas, entre otros, sin que estuviese presente la figura inmaterial del patrimonio cultural.

Llull-Peñalba (2005) analiza la concepción actual de patrimonio cultural desde las disciplinas que se han dedicado a su estudio (la historia, el arte, la educación, la religión, el derecho y la antropología) y señala al coleccionismo de objetos como el inicio de lo que hoy se conoce como patrimonio cultural. Esto, debido a que en la Antigüedad la noción de patrimonio "tiene el significado unívoco de riqueza personal y que los mecanismos de consecución de elementos patrimoniales incluían viajes de exploración, intercambios comerciales y relaciones diplomáticas, pero con mayor frecuencia se asociaron a la adquisición de botines de guerra" (Llull-Peñalba, 2005, p. 182). Sin embargo, este pensamiento particularista, 
centrado en la propiedad y disfrute privados, ha evolucionado hasta concebir la existencia y selección de referentes culturales (manifestaciones y objetos de creación humana) significativos para la identidad y la cultura de un colectivo de personas.

La idea de seleccionar unos referentes culturales sobre otros constituye un proceso de exclusión e inclusión en el patrimonio, convirtiéndolo en escenario de tensiones y negociaciones. Según Llorenç Prats (1997), en ciertas comunidades existen determinados "referentes simbólicos patrimoniales" cuyo valor ha sido transmitido de generación en generación y se relaciona con la capacidad de dichos referentes para representar una identidad. Además, estos deben pertenecer a un pool patrimonial (naturaleza, historia e inspiración creativa) de fuentes extraculturales de legitimación, así como también gozar de cierto aprecio y reconocimiento por parte de una comunidad que se identifica con dicho patrimonio y que, por lo tanto, lo valora. En este sentido, empieza a tejerse una red de prácticas, escenarios, decisiones y actores que movilizan ese patrimonio, es decir, lo activan.

Fontal (como se citó en Gómez, 2013) sustenta que, si bien todo puede ser patrimonio, solamente lo es aquello que ha pasado por un proceso de patrimonialización, relacionado con la forma en que el ser humano comprende, valora y respeta lo que ha seleccionado como patrimonio. Así, la patrimonialización se presenta como una selección y activación de valores de los referentes simbólicos de una cultura para que se conviertan en patrimonio. Este proceso se da en un contexto social, político o económico, media entre intereses y valoraciones de los grupos sociales implicados y puede o no formalizarse normativamente por las políticas del Estado.

En Colombia, a comienzos del siglo XX, jurídicamente no existía la noción de patrimonio cultural. Por tal razón, este artículo aborda la categoría de patrimonialización como el ejercicio de activación y exaltación de un referente simbólico dominante, la Virgen del Rosario de Chiquinquirá, por parte de la alianza Estado-Iglesia católica, procurando crear y transformar valores al coronarse como patrona y reina de Colombia.

\section{El patrimonio cultural como insumo para la construcción del Estado nación}

Con el declive del feudalismo y la llegada de la Modernidad con movimientos como la Ilustración, nace la estructura político-administrativa y territorial del Estado nación, y, con ella, la necesidad de consolidar una identidad común para un territorio nacional (Arrieta, 2010; Granato y Oddonade, 2010). De tal forma, el Estado, tal como se conoce hoy en día, emerge como una construcción jurídica política asentada en las bases 
teóricas de finales del Medioevo. Uno de los autores más representativos del siglo XVI fue Nicolás Maquiavelo, quien encontró en la palabra Estado -en italiano, lo stato, es decir, lo inmóvil o lo establecido- un término preciso para sintetizar sus controvertidos puntos de vista acerca de "las bases y procedimientos idóneos para la conservación del poder público" (Maquiavelo, 1980, p. 130).

La nación, por su parte, se concibe desde la existencia de comunidades que reconocen una unidad de origen o una historia común de relaciones sociales y de parentesco, obien una administración territorial o una identidad cultural reconocida. Para Eric Hobsbawm (2004), nación puede definirse como la pertenencia a un pueblo que comparte un mismo territorio o las pretensiones sobre un espacio ancestral, que poseen una lengua común, una misma historia y tradiciones. Para otros, el concepto de nación es más político que cultural y es concebido como una asociación que puede incluir grupos de distintos orígenes, los cuales deciden unirse y autogobernarse en un determinado territorio (Cabeza, 2015).

En los procesos de construcción de nación, suele atribuirse al patrimonio cultural una pretendida importancia (García, 2008), debido a que este privilegia formas específicas de incorporación del pasado al presente y otorga valoraciones concretas, hegemónicas y oficiales a ciertos referentes simbólicos de la cultura.

Para el caso de América Latina, la construcción del discurso nacionalista hace énfasis en la protección de culturas antiguas, autóctonas, hispánicas o prehispánicas y busca mantener vivos algunos referentes culturales del pasado para darles continuidad, diferenciarse como nación y, en últimas, consolidar una soberanía, una unidad y una identidad nacional (Quintanal, s.f.) como formas específicas de incorporación del pasado al presente.

Las valoraciones atribuidas, desde el Estado, a los referentes simbólicos de la cultura, se convierten en políticas nacionales que impulsan la formación de la identidad nacional. Así, "El Estado, las autonomías o los municipios, sus respectivos gobiernos, no actúan en este sentido de forma diferente, sino con mayor o menor intensidad según sus medios, pero también según sus urgencias identitarias" (Prats, 1997, p. 34). Lastimosamente, para Quintanal (s.f.) las políticas nacionales que impulsa el Estado, dentro de una idea de nación, han reducido el valor del pasado a lo que resulta ser significativamente necesario para justificar el presente. 


\section{Referentes simbólicos en la construcción del Estado nación colombiano: la Virgen del Rosario de Chiquinquirá}

La evangelización católica fue un proceso histórico que influyó en la transformación de un sistema de creencias y prácticas religiosas consolidadas en los habitantes del recién conquistado territorio que hoy representa Colombia. No fue sino hasta finales del siglo XIX, que se forjó una idea contundente de nación en Colombia, según Mena (como se citó en Erazo, 2008).

La nación colombiana se configura a partir de una serie de hechos y tejidos históricos-políticos-culturales ocurridos hacia la década de los $80^{\prime}$ del siglo XIX, los cuales permiten poner en marcha una serie de dispositivos que hacen posible la interiorización de los valores simbólicos y culturales que hoy forman parte de la nación colombiana. (p. 37)

Así, las diversas formas de representación simbólica se fueron arraigando en la sociedad colombiana y dieron valor, en el presente, a significados del pasado. Esta apropiación social genera identidad y provee un sentido y una forma de pertenecer.

En consecuencia, el propósito del presente apartado es abstraer y evidenciar los elementos centrales que caracterizaron y consolidaron el símbolo religioso, la Virgen del Rosario de Chiquinquirá, como representación legítima de una concepción naciente de nación en la Colombia de finales del siglo XIX y de comienzos del XXI. Asimismo, se quiere dar a conocer la importancia de una imagen-objeto sagrado como antecedente del milagro, y la narrativa oficial de la Virgen como una de las primeras prácticas de activación patrimonial. Además, se vincula la naturaleza de las prácticas y los sujetos involucrados en la producción y configuración del espacio religioso local en Chiquinquirá.

\section{La Virgen del Rosario de Chiquinquirá, una manta de algodón}

El uso de las imágenes religiosas se vio fortalecido en el Sacrosanto y Ecuménico Concilio de Trento (1847), escrito en 1564, en el cual la Iglesia reglamentó el ya desarrollado uso de las artes con fines de adoctrinamiento, eso sí, bajo supervisión de las autoridades eclesiásticas. El desarrollo de las imágenes en la pintura religiosa en el Nuevo Reino de Granada fue tardío y casi nulo. 
Por ello, el trabajo realizado por Alonso de Narváez en Tunja hacia el año de 1562 resulta ser objeto de interés. Este corresponde al lienzo de la Virgen, que fue renovado en Chiquinquirá; se trata de una pintura a base de pigmentos naturales del siglo XVI. El lienzo "es lo más parecido a un temple sobre tela de algodón y mide 119 x 126 centímetros" (Gil, 1986, p. 83) ${ }^{1}$. Esta pintura, en la que en su centro se encuentra la Virgen con el niño en sus brazos; al lado derecho de ella, San Antonio de Padua; y al lado izquierdo, San Andrés, pronto se convertiría en la imagen de la Virgen de Chiquinquirá, objeto de culto por su milagrosa renovación.

Este lienzo fue pintado por encargo del entonces encomendero de Suta, Antonio de Santa Ana, devoto de la Virgen, quien ordenó que fuera elaborado para ponerlo en el adoratorio de Suta, donde, en otrora, los misioneros catequizaban a los indígenas (Briceño, 1987). Una vez terminado el encargo, en 1562, Antonio de San Ana llevó el lienzo hacia Suta, donde permaneció por varios años hasta que el cura doctrinero Leguizamón se dio cuenta que el lienzo ya era muy viejo, y estaba desgastado y roto, por lo cual le pidió a Santa Ana que le cambiara esa imagen por otra.

Tras recibir el lienzo ajado, el encomendero Santa Ana lo hizo llegar a su esposa Catalina de Irnos, que se encontraba en Chiquinquirá. El lienzo ajado fue llevado por indígenas “(...) siguiendo las órdenes de Antonio de Santana. El lienzo fue puesto en la capilla de Chiquinquirá, que estaba afuera de la casa de Antonio de Santana, y reposó allí hasta que María Ramos² la sacó del olvido en 1586" (Bohórquez, 2016, p. 24). Así, es posible establecer que el lienzo de la Virgen llegó a Chiquinquirá después de 1578,

\footnotetext{
1 "La tela fue confeccionada con hilos de algodón en telar manual por los indios, atendiendo a datos históricos. La pintura de la sagrada imagen fue elaborada al temple, con tierras y zumo de vegetales y flores. El lienzo con la pintura de la Virgen de Chiquinquirá, que se venera en la Basílica de Chiquinquirá, es el lienzo original. La sagrada imagen no ha sido retocada nunca por ningún pintor. A pesar de la debilidad de los materiales usados para la pintura, los factores climáticos (luz, aire, humedad, polvo) de los maltratos de viajes y procesiones, los apliques (joyas, rosarios, condecoraciones, medallas, alfileres y tornillos, etc.), a lo largo de cuatro siglos y medio, el humo de las lámparas y velas; $\mathrm{y}$, en los últimos decenios, la luz eléctrica demasiado cerca al lienzo, la luz de los reflectores y flash de fotografías y otros graves descuidos, se mantiene la imagen de la Santísima Virgen de Chiquinquirá" (Álvarez, 1986, p. 32). 2 María Ramos era originaria de Guadalcanal, España. Según Ariza (1969), María Ramos llegó a la ciudad de Tunja en el año de 1586, junto con su cuñado Francisco Aguilar Santana, hermano de su esposo, Pedro Rivera de Santana. Los hermanos Santana eran sobrinos del encomendero Antonio de Santana. En la versión de Tobar y Buendía (1694) no se explica por qué, al llegar al encuentro con su esposo, María Ramos se decepcionó y huyó a Chiquinquirá, donde se encontraba Catalina de Irnos, viuda de Antonio de Santana, y le pidió posada. Sin embargo, en la versión de Flórez de Ocáriz (1674) se expresa que el esposo de María Ramos se encontraba de amores con otra mujer y por lo tanto, la desprecia, lo cual dio origen al desconsuelo y tristeza de María Ramos, quien terminó refugiándose en la consagración y oración a la Virgen.
} 
es decir, ocho años antes del milagro y, aproximadamente, tres años antes de la muerte del encomendero.

\section{El milagro de la renovación: «Madre, mira a la madre de Dios, que está en el suelo», un relato oficial}

El milagro de Chiquinquirá se manifestó en la renovación de un lienzo o manta de algodón de la imagen de la Virgen. El día 26 de diciembre de 1586, según la primera publicación sobre estos detalles,

(...) habiendo estado retirada en la capilla, como lo tenía de costumbre, el 26 de diciembre de 1586 (...) entre las ocho y nueve de la mañana, después de haber estado la devota María Ramos más de dos horas en oración, ofreciendo sus ruegos a la sacratísima Virgen María (...) Levantándose de su asiento, para salir de la Capilla, y poniendo sus ojos en el lienzo (...) hizo una profunda reverencia, a este tiempo pasaba una india cristiana y ladina, llamada Isabel (...) llevaba la india de la mano a un niño mestizo llamado Miguel de cuatro a cinco años de edad. Al pasar por la puerta de la Capilla le dijo el niño a la india, madre, mira a la Madre de Dios, que está en el suelo, volvió la india, a mirar hacia el Altar, y vio que la imagen estaba en el suelo parada, despidiendo de si un resplandor (...) que llenaba de claridad toda la Capilla (...) asombrada y muy despavorida le dijo en altas voces a María Ramos, que iba saliendo de la Capilla: Mira, mira señora, que la Madre de Dios se ha bajado a tu lugar, y está allí en tu asiento parada, y parece que se está quemando: volvió María Ramos el rostro, y vio la imagen de la Madre de Dios (...) con una hermosura celestial, divina, con unos colores muy vivos, y alegres, y con el rostro muy encendido, y colorado, despidiendo de si un grandísimo resplandor (...). (Tobar y Buendía, 1986, pp. 24-26)

Aunque Flórez de Ocáriz (1674), Alonso de Zamora, Parra Pérez y Andrés Mesanza (1701) también se refirieron al lienzo sagrado, la obra de Tobar y Buendía es reconocida como la versión oficial de la renovación del lienzo, ya que fue publicada, con autorización de la orden de predicadores, como la versión oficial y verdadera del milagro del lienzo.

Después del suceso del milagro, Juan de Figueredo, cura de Suta, y el escribano Diego López de Castiblanco acudieron a inspeccionar y documentar lo sucedido. Levantaron una especie de actas con los testimonios de las personas que presenciaron el milagro. Para septiembre de 1586, el arzobispo de Santafé fray Luis Zapata interrogó a los testigos del suceso, por medio del padre Gerónimo de Sandoval, cura y vicario de la Villa de Nuestra Señora de Leyva, y con ayuda del notario Andrés 
Rodríguez. Para Mesanza (citado en Ramírez, 1986), el proceso eclesiástico sobre la veracidad del milagro duró dos años, de 1587 hasta 1589. Este y las 13 declaraciones recogidas entonces se encuentran hoy en el archivo parroquial de Chiquinquirá.

De este modo para Llanos (2004), el hecho sobrenatural y milagroso se convierte en una verdad histórica, plasmada en documentos y libros, que se institucionaliza como resultado de un proceso jurídico de legitimación. Así, con la legitimación del milagro, se le atribuyen nuevos valores al lienzo de la Virgen, entre los cuales se encuentra lo sagrado; y, por consiguiente, es aprehendido selectivamente por su representación de lo sobrenatural. El antecedente del milagro es una primera práctica de activación patrimonial y expone al símbolo sagrado ${ }^{3}$ como una potencia magnética que interacciona e incide en la posición y reconocimiento social de sus custodios.

\section{El santuario de Chiquinquirá: la producción identitaria de un espacio desde la dimensión religiosa}

A través de los siglos se han elaborado varios textos literarios con el fin de consolidar y legitimar el hecho del milagro de la renovación como fundamento en la producción de una dimensión religiosa del espacio en Chiquinquirá. El primer relato fue el del fray Dominico Tobar y Buendía, escrito en 1694, Verdadera histórica relación del origen, manifestación y prodigiosa renovación por sí misma y milagros de la imagen de la Sacratísima Virgen María Madre de Dios Nuestra Señora del Rosario de Chiquinquirá. Esta narración fue publicada en una segunda edición por el Instituto Caro y Cuervo en 1986.

Como encargado de la Comisión corográfica de Nueva Granada en 1853, Manuel Ancízar mencionó la gran devoción y el sinnúmero de peregrinos que arribaban, para la época, a Chiquinquirá, en uno de sus capítulos de la Peregrinación de Alpha por las provincias del norte de la Nueva Granada entre 1850 y 1851. Chiquinquirá representa un espacio producido y configurado a partir del milagro de la renovación, relato al que se acude con frecuencia cuando se habla de los orígenes de la ciudad. Desde estos discursos territoriales, a aquel milagro se le atribuyó, y se le atribuye, el nacimiento de la ciudad de Chiquinquirá, cuya particularidad religiosa data de los orígenes mismos de su conformación como territorio anterior a la Conquista.

\footnotetext{
${ }^{3}$ Para Geertz (1973), “los símbolos sagrados tienen la función de sintetizar el ethos de un pueblo -el tono, el carácter y la calidad de su vida, su estilo moral y estético- y su cosmovisión, (...) sus ideas más abarcativas acerca del orden" (p. 89). En torno a ellos giran representaciones de identidad, tradiciones, continuidades y discontinuidades.
} 
Según aseguran Cornejo y Mesanza (como se citaron en Peralta, 2011):

Los indios de toda esta comarca tenían un famoso templo en la laguna de Fúquene ${ }^{4}$, y el fanatismo con que veneraban a su ídolo era tal, que continuamente venían en gran número de los lugares más remotos a ofrecerle dones y sacrificios. (p. 46)

Las conocidas peregrinaciones muiscas, acciones rituales ostentosas, significaban para los españoles idolatrías demoníacas que pronto tuvieron que ser extirpadas. Los españoles creyeron reemplazar los cultos paganos de los indígenas por cultos impuestos desde la religión católica (Adarve, 2007). Sin embargo, lo que se dio fue una mimesis que, para el autor, fue generada en un "espacio altamente simbólico, la laguna de Fúquene, asociada a unas prácticas intensamente ritualizadas en la tradición religiosa muisca, y cuyas acciones significantes están dotadas de un fuerte contenido sagrado [...]" (Adarve, 2007, p. 435). Así, se muestra cómo este fenómeno religioso y sus consecuentes y continuas prácticas rituales, como las romerías y peregrinaciones, dan contenido a la significante imagen de la Virgen de Chiquinquirá.

La mimesis fue una estrategia de resistencia cultural que, ante las profundas grietas producidas por la acción colonial en su sistema simbólico religioso, esto es, su sacralizada ancestral, el nativo negoció una reelaboración simbólica, a partir de sus viejas prácticas significativas en un contexto nuevo: la imagen religiosa: el icono católico colonial, arraigada en un espacio sagrado nativo. (Adarve, 2007, p. 436)

En una ocasión, el cura de Chipaque erigió en su pueblo una capilla en honor a Nuestra Señora de Chiquinquirá, con el fin de convencer a los indios de que se podía alabar a la reina del cielo sin necesidad de emprender un viaje tan largo (Chipaque se encuentra a 20 leguas de distancia de Chiquinquirá). Sin embargo, ellos le decían: “es cierto, mi amo Cura; más siempre iremos de cuando en cuando a Chiquinquirá, porque estamos acostumbrados desde tiempo de nuestros padres a ir bien lejos a nuestras devociones" (Ancízar, 1853, p. 26).

Comolo aseguran las primeras crónicas las numerosas peregrinaciones hacia Chiquinquirá continuaron. La llegada de peregrinos organizados o no a Chiquinquirá nutría un espacio con gestos y ritos que implican diversas formas materiales y simbólicas que se traducen en la producción religiosa

${ }^{4}$ Cercana a Chiquinquirá, en el Oeste del departamento de Boyacá. 
de una espacialidad. Ancízar (1853) recuerda que al llegar a Chiquinquirá observaba una gran serie de cruces puestas a la vera del camino; curioso, le preguntó al baquiano con quien viajaba sobre este espectáculo, y este le respondió: “Todo peregrino que por primera vez pasa esta cumbre, de viaje a Chiquinquirá a cumplir promesa, pone su cruz de madera, o la graba en las peñas o en la corteza de los árboles, conforme vaya de prisa o despacio" (p. 25).

Después del traslado del lienzo con la imagen de la Virgen desde la capilla en Suta hasta los aposentos de Antonio de Santana en Chiquinquirá, cerca de 1578, donde sucedió el milagro en 1586, se dieron numerosos cambios en la organización del espacio, entre ellas, la construcción de una nueva capilla a manos de los indios catequizados de la naciente aldea, supervisados por Juan de Figueredo, a cuarenta pies del lugar donde sucedió el milagro (Tobar y Buendía, 1986). Así, la conformación de los tempranos y numerosos flujos de peregrinos a la zona y la donación, en 1588, de un terreno por parte de Antonio de Santana (Freide, 1960) para la construcción del primer templo en mampostería, permitieron que en el mismo año el Arzobispo de Santa fe erigiera la parroquia de Chiquinquirá, según Ariza (como se citó en Ramírez, 1986): “no en función de pueblo alguno que no había allí, sino en consideración a la creciente afluencia de peregrinos a quienes era necesario atender permanentemente" (p. 138).

Tras la muerte de Santana, la viuda Catalina se constituyó como la primera autoridad ordenadora para vender y adjudicar los solares que fundaron la población. Cientos de devotos de la virgen se quedaron en el lugar del fenómeno "abriendo negocios de comidas y bebidas y de precarios alojamientos para las crecientes romerías que el milagro originó" (Rojas, 1999, p. 17). Así nació Chiquinquirá, una ciudad que no tiene fundación hispánica, sino que se origina a raíz del milagro de la renovación.

Sin embargo, entre 1592 y 1636, las órdenes religiosas de agustinos, franciscanos, dominicos y hasta el clero secular pretendieron el santuario de Chiquinquirá 5 . Una de las ventajas de los dominicos ante las otras órdenes religiosas y ante el clero secular fue su compromiso de edificar un convento. La orden de predicadores llegó a Tunja en 1541 y fundaron en Boyacá 36 doctrinas: las aledañas al Convento del Eccehomo (Londoño, 2008). Para el 12 de mayo de 1658, los Padres dominicos erigieron y señalaron al Convento "sitio y Santa Casa de Nuestra Señora de Chiquinquirá" (Peralta, 2011, p. 113).

\footnotetext{
${ }^{5}$ Para más información sobre el proceso acaecido por los dominicos para lograr la doctrina de Chiquinquirá véase Tobar y Buendía (1694) y Peralta (2011).
} 
En los años posteriores a la instalación formal de la orden de los padres dominicos en Chiquinquirá, las peregrinaciones se convirtieron en parte de la vida normal de los chiquinquireños. El santuario, materializado en una monumental basílica, extendió la cobertura del culto ${ }^{6}$ a otras regiones, trascendió fronteras y se convirtió en un catalizador multicultural. Así, los habitantes empezaron a considerarlo elemento de su identidad.

Rinschede (1992) afirma que "numerosos lugares religiosos son correspondientemente sitios nacionales"7 (p. 53). De esta forma, solo es posible entender la construcción histórica del referente simbólico de la Virgen de Chiquinquirá y el protagonismo que tuvo su proceso de patrimonialización en la consolidación del Estado nación colombiano, si se vinculan a este proceso los elementos anteriormente desarrollados.

\section{Consagración de la alianza Estado-Iglesia católica: comprendiendo el Estado confesional de 1919}

Con el espaldarazo dado a la Iglesia católica en la Constitución de 1886, esta se seguía posicionando como la institución religiosa única y capaz de ejercer un verdadero control sobre la sociedad civil. Así quedó contemplado en el Concordato de $1887^{8}$.

Mientras finalizaba una guerra civil e iniciaba la Guerra de los Mil Días ${ }^{9}$, las élites de la República entronizaron el Sagrado Corazón como

\footnotetext{
${ }^{6}$ El culto a la Virgen del Rosario de Chiquinquirá sobresale entre otros surgidos a advocaciones marianas “(...) porque trascendió las fronteras del Nuevo Reino de Granada y se expandió a poblaciones distantes de otros virreinatos y hasta la misma España (...) Fue la primera aparición que trascendió en el Nuevo Reino de Granada" (Llanos, 2004, p. 109). El culto a nuestra Señora de Chiquinquirá, de origen mestizo, se desarrolla en el tiempo, es dinámico e involucra cada vez a nuevos actores que lo llenan de situaciones y significaciones.

${ }^{7}$ Traducción de los autores, original en inglés "numerous religious places are correspondingly national sites". ${ }^{8}$ Un concordato es un tipo de acuerdo entre la Santa Sede (como representante de la Iglesia católica) y un Estado para regular las relaciones entre ellos, en ámbitos de mutuo interés. Este posee la categoría jurídica de Tratado Internacional. El concordato de 1887 se realizó entre León XIII y el presidente de la República de Colombia Rafael Núñez.

${ }^{9}$ La Guerra de los Mil Días fue una guerra civil de Colombia disputada entre el 17 de octubre de 1899 y el 21 de noviembre de 1902, en un principio entre el Partido Liberal y el gobierno del Partido Nacional en cabeza del presidente Manuel Antonio Sanclemente, quien fue derrotado el 31 de julio de 1900 por José Manuel Marroquín Ricaurte, representante del Partido Conservador, en alianza con el liberal Aquileo Parra. A partir de entonces, y a pesar de dicha alianza, la guerra continuaría entre liberales y conservadores históricos.
} 
símbolo masculino de un imaginario ${ }^{10}$ religioso. Este se consolidó como símbolo garante de paz y de reconciliación nacional, como lo menciona Rojas (1999): “Esta vinculación del símbolo como garante de paz y baluarte cívico permitió su penetración y arraigo en la cultura local" (p. 66). Por su parte, la Iglesia entendió que, para mantener y expresar el significado simbólico del Sagrado Corazón a las comunidades campesinas, debía distanciarse del lenguaje y rituales sofisticados, al menos en cierta medida (Rojas, 1999). Así, la entronización del Sagrado Corazón, como símbolo religioso masculino, imprime un carácter del tipo de nación que se espera para una sociedad conservadora, o, mejor dicho, un gobierno conservador que quiere proyectar una sociedad conservadora.

La Iglesia católica en Colombia continuó su empresa, “entendió la importancia de resacralizar el tiempo y el espacio, y emprendió una vasta tarea para asentar este [ahora nuevo] imaginario rosarista con la colaboración de diferentes sectores sociales" (Rojas, 1999, p. 68). A la Orden de Predicadores (O.P.) se le atribuye la creación de la cofradía del Rosario, por lo cual, la orden de los dominicos tiene como patrona devocional a la Virgen del Rosario. De manera que, con el rosario como bandera ${ }^{11}$ y con el lema "familia que reza unida, permanece unida", se imponía una representación simbólica del culto a la Virgen del Rosario por parte de la Iglesia católica y bajo el auspicio del gobierno de la época. Esto llevó a que un pueblo, en su mayoría analfabeta, comprendiera los misterios de Jesús y de la Virgen María de una manera práctica, repetitiva y didáctica. Pronto, el rezo del rosario fue la práctica de religiosidad popular más significativa entre los devotos de la, ya conocida, Virgen de Chiquinquirá ${ }^{12}$.

En este sentido, el objetivo de este apartado responde a la pregunta: ¿Cómo se consagra la alianza Estado-Iglesia católica con la exaltación de un referente simbólico dominante como la Virgen del Rosario de Chiquinquirá?

\footnotetext{
${ }^{10}$ Para Rojas (1999), un imaginario es la "producción espiritual de las élites, a través del ejercicio del poder, influyen sobre la mentalidad de las colectividades para crear o construir nuevos patrones de conducta y comportamiento. Los imaginarios tocan el terreno de la política y su principal arma es la propaganda" (p. 14).

${ }^{11}$ En 1891 el Papa León XIII incitaba al clero y a los fieles del mundo a la devoción por el Rosario, al mismo tiempo que consagraba al mes de octubre como el mes dedicado a la Virgen del Rosario. La iglesia colombiana hizo lo propio y entendió la necesidad de sacralizar el tiempo y el espacio, así que se preocupó por extender la devoción por el Rosario en todo el territorio. En 1897 se estableció en el santuario de la Virgen del Rosario de Chiquinquirá, al primer domingo de octubre de cada año como el día de la fiesta del Rosario.

${ }^{12}$ Entrevista con doña Rosa María Rojas, devota de la virgen del Rosario de Chiquinquirá, quien cuenta que desde niña su mamá, la enseñó a rezar el rosario y que aún hoy en día reza dos rosarios para acostarse y dos antes de levantarse (9 de junio de 2018).
} 
La virgen representa un referente cultural en la religiosidad católica colombiana y específicamente en la boyacense. A la hora de caracterizar los elementos que configuran la activación patrimonial de la Virgen del Rosario de Chiquinquirá como referente simbólico, desde una realidad política de comienzos del siglo XX en Colombia, se debe abordar críticamente al menos dos atmósferas. Por un lado, cómo la Virgen del Rosario de Chiquinquirá es puesta en un primer plano político para legitimar la concepción de una nación, siendo referente simbólico patrimonial construido en la Colonia, afianzado en la República con "las procesiones para conjurar las pestes y las epidemias, las visitas de la Imagen sagrada a la capital de la República y las romerías de los peregrinos por aldeas y pueblos [...]" (Londoño, 2008, p. 89). Por otro lado, cómo el ambiente confesional originado con la constitución de 1886 consagró una alianza Estado-Iglesia católica en Colombia, que terminó exaltando con nuevos valores a un referente simbólico como la Virgen del Rosario de Chiquinquirá, al ser coronada como patrona y reina.

Para entender las estrategias de activación sustentadas por el Estado y la Iglesia católica en su idea de nación y profundizar en la manera en que estas se vinculan a la idea de la Virgen del Rosario de Chiquinquirá como patrimonio cultural, es necesario, desde una perspectiva académica, recabar en los momentos históricos de la Regeneración, la Hegemonía conservadora y, por lo tanto, en el surgimiento del Estado nación. Estos se toman como momentos históricos que, al instrumentalizar intereses políticos en la Colombia de la época, legitimaron una concepción de nación y coronaron como patrona y reina a un dominante referente simbólico: la mestiza Virgen del Rosario de Chiquinquirá.

\section{Operación de la reina, madre y patrona: un proyecto político}

El proyecto político de la Regeneración surge en las últimas décadas del siglo XIX y es liderado por el presidente Rafael Núñez. Según Londoño (como se citó en Madrigal, 2012):El proyecto de Núñez, la Regeneración, puso énfasis en el orden y progreso económico (...) su pragmatismo lo llevó a reconocer a la Iglesia como parte orgánica de la sociedad colombiana y de suma importancia para la consecución de la tranquilidad social. (p. 232)

De esta manera, el presidente Núñez le dio legitimidad a su gobierno, reconociendo la importancia que la religión católica tenía para la sociedad colombiana y la instrumentalizó para obtener el control ideológico del sistema político. 
En el periodo de la Regeneración, la Iglesia y el Estado trabajaron conjuntamente en la consolidación de un Estado nación, cuyo objetivo era cambiar la organización que tenían el gobierno y la sociedad colombiana, a partir de lo establecido por la Constitución de 1863, con la que crearon los Estados Unidos de Colombia y con la que el país se convirtió en una república federal. El movimiento regenerador estaba conformado por los conservadores y los liberales moderados, en oposición a los liberales radicales, los cuales ostentaban el poder. Para ese entonces, el Estado confesional hizo énfasis en la regeneración, lo cual implicaba, entre otras cosas, rescatar las principales características de la identidad nacional para fundamentar en ellas el nuevo sistema político.

Con la Regeneración propuesta por el presidente Rafael Núñez, Colombia se consolidó como un Estado confesional ${ }^{13}$ y los enfrentamientos entre partidos, liberales y conservadores, consolidaron la guerra por un orden político legítimo en el proceso de formación del Estado nacional. Resulta paradójica la forma en que un Estado confesional, en 1919, consagra la alianza entre el Estado y la Iglesia católica en Colombia, activando un referente simbólico como la Virgen del Rosario de Chiquinquirá, por medio de su coronación. "La Virgen es ya decididamente conservadora. Para ello, había tenido que pasar innumerables contiendas y guerras civiles que se remontan al temprano proyecto libertador en la primera mitad del siglo XIX" (Ferro, 2004, p. 104). Lo anterior, pese a que las posturas, en términos de teoría política, que influenciaron la revolución de independencia, propendieron principalmente por la separación entre el Estado y la Iglesia católica. Esto muestra dos lados, uno de ellos "[...] liberal y laico impulsado por grupos de letrados liberales, sobre todo abogados, médicos, algunos de ellos militares y unos pocos eclesiásticos y otro, sustentado en la alianza de gran parte de la Iglesia católica con el partido conservador" (Mesa, 2013, p. 6).

Este último permitió la coronación de la Virgen del Rosario de Chiquinquirá como patrona y reina de los colombianos en 1919 - un presidente liberal no lo hubiese permitido-. Así, el presidente Marco Fidel Suárez aprovechó una “[...] identificación estrecha de la Iglesia con el partido conservador que prohijó la construcción de un Estado nación fundado en el catolicismo y la herencia hispánica a partir de 1886" (González, 1997, p. 30) y estableció una alianza entre las elites criollas y la iglesia en búsqueda del control político en la naciente república colombiana.

\footnotetext{
${ }^{13}$ El Estado confesional es el que se adhiere a una religión específica, llamada religión oficial (iglesia estatal o iglesia establecida). Esta situación puede ser simplemente resultado de los usos y costumbres o tradición, o reflejarse en su legislación, especialmente en la Constitución del país. Para el caso de Colombia, sus instituciones políticas estaban ligadas a la Iglesia católica.
} 


\section{La exaltación de un referente simbólico patrimonial: la coronación de la Virgen del Rosario de Chiquinquirá}

La coronación de la Virgen ${ }^{14}$ del Rosario de Chiquinquirá representa una estrategia de activación, al poner en primer plano político un símbolo dominante de arraigo popular como una representación legítima. El evento de la coronación de la Virgen, llevado a cabo el 9 de julio de 1919, fue instrumentalizado por unos intereses políticos propios del periodo de la Hegemonía conservadora en Colombia. Con la coronación, el binomio de la Iglesia y el Estado colombiano patrimonializaron un referente cultural, transportando su valor original de culto y mostrándolo ahora con nuevos atributos: coronada y consagrada como la patrona de Colombia, la virgen nacional.

Más allá de la relevancia social y económica que tuvo el hecho mismo de la coronación, lo reseñable es que se consagró, en el naciente Estado colombiano, un culto mariano expuesto en un plano político por parte del Estado y la Iglesia católica, y se legitimó una vinculación estrecha entre la identidad nacional y el, ya consagrado, culto a la Virgen del Rosario de Chiquinquirá. Así lo presume el fray Dominico Andrés Mesanza (1934): “Colombia es posesión de María, como María es posesión de Dios. Mientras el pueblo neo-granadino sepa doblar la rodilla ante la Madre del Rey de reyes, las naciones respetarán la bandera colombiana, alfombra de su trono" (p. 4). Esta activación patrimonial le confirió a la Virgen del Rosario de Chiquinquirá nuevos valores y, años después, como referente simbólico dominante en un Estado nación colombiano, entró a disputar sus significados y valores con una sociedad colombiana declarada laica desde la constitución de 1991.

\footnotetext{
${ }^{14}$ La coronación canónica es un rito litúrgico católico relativamente nuevo, es decir, no data de los inicios del cristianismo, y consiste en la imposición de una corona o coronas a un icono o imagen determinada, su finalidad, resaltar la devoción a una imagen de la Virgen María. El rito de coronación de la Virgen data del siglo XVI; y quien comenzó la costumbre de coronar las imágenes de la Virgen fue el capuchino fray Jerónimo Paolucci (1552-1620). Sin embargo, es el Papa Juan Pablo II quien promulga el ritual de coronación para la Iglesia católica en el siglo XX. Existen tres tipos de coronaciones canónicas: la pontificia, concedida por el pontífice; la diocesana, concedida por el obispo de la diócesis; y la litúrgica, que no necesita permiso alguno y la puede realizar cualquier eclesiástico. Los criterios para la coronación a una imagen de la Virgen es que esta tenga, desde su creación material, más de cincuenta años de antigüedad, que presente la comprobación de los favores recibidos y que goce de gran popularidad.
} 


\section{Conclusiones}

Históricamente la categoría teórico-práctica de patrimonio cultural emerge en un contexto donde el hombre se identifica a sí mismo con base en su pasado. Con la finalización del Medioevo en el periodo denominado Ilustración, se suscitan controversias respecto a la importancia que tiene el pasado para el ser humano.

Por otro lado, la categoría de patrimonialización es entendida, la mayoría de las veces, como una formalización normativa propuesta por las políticas del gobierno, encaminada a la salvaguardia, protección, manejo o difusión del patrimonio cultural tanto mueble como inmueble; sin embargo, también obedece a nombrar o reconocer un referente cultural como patrimonio. En ese sentido, esta categoría puede darse desde el individuo, por medio de la atribución de valores a los referentes simbólicos vinculados con la identidad, el uso, o el reconocimiento social, lo cual no siempre conlleva ejercicios de nombramiento o declaratorias estatales.

La consolidación de los Estados modernos surge de la necesidad de encontrar elementos comunes que formen referentes de identidad en su interior. Con el Estado, como aparato de poder constituido, se acoge una serie de referentes simbólicos que, a partir de una activación patrimonial, otorga y acoge valores identitarios para la sociedad.

En el caso colombiano, la formación de Estado nación no es diferente. Dicha formación se establece históricamente a finales del siglo XIX y comienzos del XX como fruto del ascenso político de la elite conservadora, en el periodo denominado La Regeneración. Allí se establecieron diversos referentes simbólicos en busca de la formación de identidad, siendo uno de ellos la religión católica, consagrada constitucionalmente, y pregonada desde el Estado.

A pesar de lo contradictorio que resulta el hecho de que solo hasta finales del siglo XIX se manifieste un Estado confesional - cuando la generalidad en las demás repúblicas nacientes de América era la separación de la iglesia y el Estado-, es bueno mencionar que ello respondió principalmente a que la Iglesia católica aprovechó los referentes simbólicos, como el de la Virgen del Rosario de Chiquinquirá, para generar un profundo vínculo con la sociedad y convertirse en un elemento de identidad nacional reconocido formalmente solo hasta la Constitución de 1886.

La Virgen del Rosario de Chiquinquirá constituye un referente simbólico en la formación de identidad en el Estado colombiano. Así, luego de un proceso de activación patrimonial, realizado por la elite política conservadora de finales del siglo XIX, se exaltó el símbolo religioso de la 
Virgen del Rosario de Chiquinquirá con el fin de legitimar una concepción de nación.

Solo resta decir que, en procura de incitar a futuros investigadores a profundizar en estudios similares, en la actualidad existe un traumatismo respecto a los elementos que forman la identidad en los Estados del siglo XXI. Esto, debido a que fenómenos culturales, políticos y económicos como la globalización, han producido un rompimiento de esta identidad, guardando la idea de referentes simbólicos identitarios que cohesionan a una sociedad respecto de un territorio, como sucedió en Colombia hasta el siglo XX con la religión católica y algunos de sus elementos, como la Virgen del Rosario de Chiquinquirá.

\section{Referencias bibliográficas}

Adarve, M. (2007). La virgen de Chiquinquirá o la mimesis sacral. En Tejeiro, C., Sanabria, F. y Beltrán, (Ed.). Creer y poder hoy (pp. 421-450). Bogotá, Colombia: Unibiblos.

Álvarez, M.C. (1986). Chiquinquirá Arte y Milagro. Bogotá, Colombia: Presidencia de la República y Museo de Arte Moderno de Bogotá.

Ariza, A. (1969). Apostillas a la Historia de Nuestra Señora del Rosario de Chiquinquirá. Chiquinquirá, Colombia: Imprenta la Rotativa.

Ancízar, M. (1853). Las peregrinaciones de Alpha. Bogotá, Colombia: Imprenta de Echeverría Hermanos.

Arrieta, I. (2010). El campo patrimonial y museístico: un espacio cultural conflictivo. Revista de dialectología y tradiciones populares 65(2), 303-336. doi: 10.3989/rdtp.2010.10

Bohórquez, A. (2016). Nuestra Señora del Rosario de Chiquinquirá: La relación de fray Pedro Tobar y Buendía (tesis de maestría). Pontificia Universidad Javeriana, Bogotá, Colombia.

Briceño, M. (1987). Chiquinquirá y los pueblos aledaños en el siglo XVI. Revista de estudios extremeños, 60 (3), 925-956. Recuperado de http://revistas.javeriana.edu.co/index.php/ univhumanistica/article/view/10133

Cabeza, Á. (2015). El Patrimonio y el Estado en la formación de la identidad cultural de Chile: desarrollo del concepto de patrimonio y su apropiación por la sociedad chilena entre los siglos XIX y XX (tesis de doctorado). Universidad de Sevilla, Sevilla, España.

Cuetos, M.P.G. (2012). El patrimonio cultural. Conceptos básicos, 207. Universidad de Zaragoza. Recuperado de https://cpalsocial.org/documentos/526.pdf

Erazo, M. (2008). Construcción de la nación colombiana. Revista de la Educación Colombiana, 11, 33-52. Recuperado de http://editorial.udenar.edu.co/revistas/rudecolombia/files/ r11_33.pdf

Ferro, G. (2004). La Geografía de lo Sagrado: El culto a la virgen de Las Lajas. Bogotá, Colombia: Ediciones Uniandes.

Flórez de Ocáriz, J. (1674). Libro Primero de las Genealogías del Nuevo Reino de Granada. Recuperado de http://babel.banrepcultural.org/cdm/ref/collection/p17054coll10/id/2518

Freide, J. (1960). Descubrimiento del Nuevo Reino de Granada y Fundación de Bogotá. Bogotá, Colombia: Imprenta del Banco de la República.

García, A. (2008). Patrimonio Cultural: Diferentes Perspectivas. Arqueología en Internet 9(2). Recuperado de https://webs.ucm.es/info/arqueoweb/pdf/9-2/angelica.pdf 
Geertz, C. (1973). La interpretación de las culturas. Barcelona, España: Gedisa. Recuperado de https://antroporecursos.files.wordpress.com/2009/03/geertz-c-1973-la-interpretacionde-las-culturas.pdf

Gil, F. (1986). La virgen de Chiquinquirá en el arte. En Arizmendi, O. (Ed.) Chiquinquirá 400 años (pp. 81-100). Bogotá, Colombia: Talleres gráficos de la Litografía el Arco.

Gómez, M. (2013). Procesos de patrimonialización en el Arte contemporáneo: diseño de un artefacto educativo para la identización (tesis de doctorado). Universidad de Valladolid, Valladolid, España. Recuperado de https://uvadoc.uva.es/bitstream/10324/3568/1/TESIS350-130920.pdf

González, F. (1997). Poderes enfrentados: Iglesia y Estado en Colombia. Recuperado de https:// www.researchgate.net/publication/44521717_Poderes_enfrentados_Iglesia_y_Estado_ en_Colombia_Fernan_E_Gonzalez_Gonzalez

Granato, L. y Oddonade, C. (2010). Una aproximación teórica a la evolución del Estado y la sociedad del mundo contemporáneo: una aproximación desde las relaciones internacionales. Tendencias, 10(2), 125-148. Recuperado de https://dialnet.unirioja.es/ servlet/articulo?codigo $=3642363$

Hobsbawm, E. (2004). Naciones y nacionalismo desde 1780. Barcelona, España: Crítica.

Latre, M. (1847). Del sacrosanto y ecuménico concilio de Trento (Ignacio López de Ayala, trad.). Barcelona, España: Imprenta de D. Ramón Martín Indar (Obra original publicada en 1564) Recuperado de http://fama2.us.es/fde/ocr/2006/sacrosantoConcilioDeTrento.pdf Llanos, H. (2004). En el nombre del padre, del hijo y del espíritu santo. Adoctrinamiento de indígenas y religiosidades populares en el Nuevo Reino de Granada (siglos XVI-XVIII). Bogotá, Colombia: Talleres gráficos de Unibiblos.

Llull-Peñalba, J. (2005). Evolución del concepto y de la significación social del patrimonio cultural. Arte, individuo y sociedad, 17, 175-204. Recuperado de https://revistas.ucm.es/ index.php/ARIS/article/download/ARIS0505110177A/5813

Londoño, R. (2008). La Virgen de Chiquinquirá: símbolo de identidad nacional. Revista Colombiana de Sociología, (31), 83-94. Recuperado de https://revistas.unal.edu.co/index. $\mathrm{php} / \mathrm{recs} / \mathrm{article} / \mathrm{view} / 10328 / 10848$

Madrigal Garzón, A.E. (2015). La formación del Estado-nación en Colombia durante el siglo XIX: el trazado histórico-social de la institución del orden político. Perspectivas internacionales, 7 (1). 219-235. Recuperado de https://revistas.javerianacali.edu.co/index. $\mathrm{php} /$ perspectivasinternacionales/article/view/845/1370

Maquiavelo, N. (1980). El Príncipe. Bogotá, Colombia: Bruguera. Círculo de Lectores.

Mesa, L. (2013). La Iglesia católica y la formación del Estado-nación en América Latina en el siglo XIX. El caso colombiano. Almanack, (6), 5-25. Recuperado de https://dx.doi. org/10.1590/2236-463320130601

Mesanza, A. (1934). La Coronación de Nuestra Señora del Rosario de Chiquinquirá. Caracas, Venezuela: Editorial Sur América.

Peralta, N. (2011). Historia de Chiquinquirá. Tunja, Colombia: Academia Boyacense de Historia. Prats, L. (1997). Antropología y Patrimonio. Barcelona, España: Ariel S.A.

Quintanal, H.S. (s.f.). Patrimonio cultural, Nación y Diversidad. LIDER, 12, 53-62. Recuperado de http://ceder.ulagos.cl/lider/images/numeros/12/5.[LIDER\%20VOL12] Patrimonio\%20Cultural\%20Nacion\%20y\%20Diversidad.pdf

Ramírez, L. (1986). Historia y teología del cuadro renovado de Nuestra Señora de Chiquinquirá. Recuperado de https://revistas.javeriana.edu.co/index.php/teoxaveriana/article/ view/22291/17343 
Rinschede, G. (1992). Forms of religious tourism. Annals of Tourism Research, 9(1), 51-67.

Rojas, V. (1999). La coronación de la virgen de Chiquinquirá: mentalidad Religiosa e Imaginario Mariano 1891-1919. Tunja, Colombia: Consejo Editorial de Autores Boyacenses.

Tobar y Buendía, P. (1986). Verdadera histórica relación del origen, manifestación y prodigiosa renovación por sí misma y milagros de la imagen de la Sacratísima Virgen María Madre de Dios Nuestra Señora del Rosario de Chiquinquirá. Bogotá, Colombia: Instituto Caro y Cuervo.

Zamora de, A., Parra-Pérez, C. y Mesanza, A. (1701). Historia de la provincia de San Antonio del Nuevo Reino de Granada. Recuperado de http://www.cervantesvirtual.com/obravisor/historia-de-la-provincia-de-san-antonino-del-nuevo-reino-de-granada-edicionde-parra-leon-hermanos-en-homenaje-al-libertador-simon-bolivar-con-motivo-delcentesimo-aniversario-de-su-muerte/html/084f28a6-a416-11e1-b1fb-00163ebf5e63.html 